\title{
Relationships of Working Conditions and Individual Characteristics to Occupational Injuries: A Case-Control Study in Coal Miners
}

\author{
Apurna Kumar Ghosh ${ }^{1}$, Ashis BhattacherJeE ${ }^{2}$ and Nearkasen $\mathrm{CHAU}^{3}$ \\ ${ }^{1}$ Department of Mining Engineering, National Institute of Technology, ${ }^{2}$ Department of Mining Engineering, \\ Indian Institute of Technology, India and ${ }^{3}$ National Institute for Health and Medical Research (Inserm), U 420, \\ Faculté de Medecine, France
}

\begin{abstract}
Relationships of Working Conditions and Individual Characteristics to Occupational Injuries: A Case-Control Study in Coal Miners: Apurna Kumar Gноsн, et al. Department of Mining Engineering, National Institute of Technology, India-This study assessed the relationship of age, poor perception of working condition, poor safety environment, poor management and supervision, risktaking behavior, emotional instability, negative job involvement, job dissatisfaction, job stress, and poor safety performance of workers to occupational injuries. This case-control study was conducted on 202 male coal miners with at least one occupational injury during a five-year period and 202 male controls with no occupational injury, matched on the job. A standardized questionnaire administered by individual interviewers was used. Data were analysed by the logistic regression method. For all workers combined, the factors with significant adjusted odds ratios (ORs) found were: $30-45$ and $>45 \mathrm{yr}$ age groups (OR vs. $<30 \mathrm{yr}$ age group: $1.80,95 \% \mathrm{Cl} 1.02-3.17$ and $2.59,1.38-$ 4.85 respectively), poor perception of working conditions $(1.61, \mathrm{Cl} 1.00-3.18)$, emotional instability (2.33, 1.04-5.22), job stress $(1.83,1.00-3.46)$ and poor safety performance of workers $(3.10,1.45-6.63)$. No significant interaction was found between these risk factors and the job. It was concluded that older age, poor perception of work conditions, poor work environment, and human behavioral factors played significant roles in occupational injuries. This information would help in implementing preventive programs to improve working conditions and management quality and to help the workers to develop positive psychological traits, but workers with negative
\end{abstract}

Received Jan 8, 2004; Accepted Sep 27, 2004

Correspondence to: A. Bhattacherjee, Department of Mining Engineering, Indian Institute of Technology, Kharagpur, 721302, India (e-mail:ashisb@mining.iitkgp.ernet.in) traits such as emotional instability and older workers should be employed in less demanding jobs.

(J Occup Health 2004; 46: 470-480)

Key words: Occupational injury, Age, Work conditions, Work environment, Human behavioral factors, Coal miners

According to International Labour Office statistics, 120 million occupational injuries and 210,000 fatal injuries occur annually at workplaces worldwide ${ }^{1)}$. They take a considerable socioeconomic toll of workers, companies and society, whereas they draw fairly little public attention. The mining industry has a high incidence of injury among all industry divisions, particularly of fatal injuries ${ }^{2}$. The incidence of injury remains high although some improvements in work conditions have been made as a result of catastrophic events and scientific progress ${ }^{3)}$. There has been little epidemiological knowledge of preventive measures as most findings have often been based on accident investigations rather than on epidemiological studies ${ }^{4-6)}$.

It is well known that a technical approach alone is not sufficient to reduce injuries ${ }^{7,8)}$. The human factor was found to make a significant contribution to injuries ${ }^{8,9)}$. Some researchers have explored the role of the social context, particularly of the safety culture ${ }^{7,8)}$. Individual characteristics of workers have been little investigated. Certain personal and impersonal factors were identified as risk factors in some industries: petrochemical industries ${ }^{10)}$, construction industries ${ }^{11-13)}$, railway firms ${ }^{14)}$, nuclear processing plants ${ }^{15)}$, transport safety ${ }^{16,17)}$, glass bottle manufacturing plants ${ }^{18)}$, and in the general population ${ }^{19-21)}$. Some authors have emphasized the roles of poor perception of working conditions ${ }^{10,22)}$, poor management and supervision ${ }^{8,23)}$, and poor safety environment ${ }^{20,24)}$, risk taking behavior ${ }^{15,25,26)}$, emotional instability ${ }^{4,27,28)}$, 
negative job involvement ${ }^{29,30)}$, job dissatisfaction ${ }^{10,28,31)}$ and job stress ${ }^{10,27,32)}$. The issue of the safety performance of workers has been little investigated although it can play a role in occupational injury ${ }^{33)}$. These factors have not been investigated simultaneously, especially amongst miners.

The present study aimed at assessing the relationships of age, poor perception of working conditions, poor safety environment, poor management and supervision, risktaking behavior, emotional instability, negative job involvement, job dissatisfaction, job stress, and poor safety performance with occupational injuries in underground coal mines.

\section{Materials and Methods}

\section{Subjects}

This investigation was a case-control study conducted on workers from three underground coal mines located in the eastern part of India which employed 2,900 miners in the period 1996-2000. The method of coal extraction was mainly the bord-and-pillar technique. The average total annual production of these mines was 440,000 tons. Only male workers were employed in underground mines. Most of the workers were from a poor socio-economic group and were illiterate. The scheduled working duration of workers was eight hours per day and they had to work six days per week. Years of experience in mines was not considered as it is very much linked with the subject's age (problem of co-linearity). The survey was conducted from July to December 2001 (six months). Based on the hypothesis that the proportion of those exposed in controls was $10 \%$, a relative risk of 2.2 , significance level $p=0.05$, power $=80 \%$, the number of case-control sets in a matched case-control study required is $n=200^{34}$. Two case-control pairs were added to prevent the possible refusal of some workers. In fact all subjects contacted participated in the study so that our study consisted of 202 case-control pairs. The cases were randomly selected from among the 780 underground workers who suffered injury at least once during the five-year period 1996-2000 (annual incidence rate of injury, 5.4\%). The injured miners were randomly selected from the injury registry maintained by the safety department of the mine. Note that the questionnaire included a description of injury for the cases. There were a few fatal and serious injuries ( 2 and 17 respectively for the same period 1996-2000, 2.4\% of total injuries); and they were excluded from the study. For each case, one control was randomly selected among the 1,591 underground miners with the same job and from the same mine who did not experience any injury in their career. Of the cases 140 were loaders who were engaged in loading coal on mine tubs at the workfaces from where coal was extracted; the others were trammers, timber mistris/majdoors, dressers, haulage workers and drillers, (62 workers). The distribution of all the injuries in the
Table 1. Distribution (\%) of all the injuries in the mines considered during 1996-2000 and of the samples according to their occupations

\begin{tabular}{lr}
\hline All the injuries in the mines (780 subjects) & \\
Loaders & 69.4 \\
Others & 30.6 \\
Trammers & 7.8 \\
Timber mistris/majdoors & 4.6 \\
Dressers & 3.3 \\
Haulage workers & 2.7 \\
Drillers & 2.4 \\
Others & 9.7 \\
\hline The cases studied (202 subjects) & \\
Loaders & 69.3 \\
Others & 30.7 \\
\hline & \\
The controls studied (202 subjects) & 69.3 \\
Loaders & 30.7 \\
Others
\end{tabular}

mines and that of the cases and controls studied according to occupation of workers is shown in Table 1 . As the loaders are the majority of the injured miners (69.4\%), two groups of occupational categories were identified: loaders and other-than-loaders. The distributions of the samples gathered according to occupation were expectedly close to that of all the injuries in the mines.

An occupational injury was defined as damage to the body regardless of its severity which resulted from an accident at work with at least one day of work day loss in addition to the day when the accident occurred and for which the subject got compensation.

\section{Study design}

The study protocol included: (1) a request for participation to the management of the three mines; (2) a standardized questionnaire called Worker's Response Device (WRD) questionnaire, which included sociodemographical data and validated questionnaires ${ }^{34)}$ assessing poor perception of working conditions ${ }^{10,22)}$, poor management and supervision ${ }^{8,23)}$, poor safety environment $^{20,24)}$, risk taking behavior ${ }^{15,25,26)}$, emotional instability $^{4,27,28)}$, negative job involvement ${ }^{29,30)}$, job dissatisfaction $^{10,30,31)}$, and job stress ${ }^{10,27,32)}$; (Table 2) and (3) a validated standardized questionnaire concerning the safety performance of the worker ${ }^{34)}$ called the Supervisor's Response Device (SRD) questionnaire (Table 2).

The WRD questionnaire was administrated at the work place for each worker (case and control). The SRD questionnaire was administrated to the immediate supervisor of the worker. All the managements of the three mines participated in the study. They introduced 
Table 2. The Worker's Response Device (WRD) and Supervisor's Response Device (SRD) questionnaires

Each question has three possible answers Yes/Cannot say/No which were assigned values of 3, 2, and 1 respectively (or 1, 2, or 3 for the items negatively formulated which are indicated by"*”).

\section{The WRD questionnaire:}

(1) Poor perception of working condition with 15 items: Is there good ventilation in the mine?*, Do you get sweated heavily at the workplace?, Is inconvenience caused due to bad light?, Are accidents common in this mine?, Is there sufficient arrangement of lights at convenient places in the mine?*, Do you feel hot at workplaces?, Is there a feeling of humidity below ground?, Is the quality of work good (absence of noxious gases, dust, etc.)?*, Are the roadways and other places inside the mine free of coal dust?*, Are the roadways watery causing slip and fall accidents?, Is there a drinking water facility inside the mine?*, Is the power supply irregular in the mine?, Do the workers need to work under a wide area of unsupported roof?, Are loose chunks of coal inside and on the roof a common phenomenon in the mine?, Is pumping of water done properly in the mine?*

(2) Poor safety environment with 13 items: Do supervisors actively discourage unsafe behavior?*, Are safety items readily available?*, Have you been trained adequately to perform your assigned job?*, Is taking risks, short-cuts or unsafe behavior acceptable to management in your workplace?, Do supervisors ignore risk-taking behavior in your workplace?, Have you observed any risk taking by other employees at your mine?, Do you receive positive feedback from supervisors for following safe work practices?*, Are safety issues you raise with your supervisor or foreman adequately dealt with?*, Are you discouraged from reporting or bringing safety issues to the attention of management?, Are hazards eliminated promptly in your workplace?*, Have you been penalized for not performing a task that you considered unsafe?*, Are safety bulletin and safety incident reports made available for you to read?*, Are the procedures used underground the same as the ones in the regulations?*.

(3) Poor management and supervision with 12 items: Are you happy with the skills and competency of your supervisor?*, Are you treated with honesty and dignity?*, Are suggestions taken from workers?*, Is priority given to the interest of the workers here?*, Is the good performance of workers appreciated here?*, Can the workers protest for the shake of their interests?*, Are the general workers considered as human beings here?*, Do the officers take care only of their own interest but not of the workers?, Do the officers try to understand the problems of workers here?*, Do you think work is done in a traditional way so there is no enthusiasm among workers?, Is there a feeling here that the prospects of the company solely depend on the officers?, Do you think most workers work here from compulsion or fear?

(4) Risk taking behavior with 11 items: Are you ready to take risks to increase your earnings?, Do you go to an unsupported area knowingly?, Does doing work at speed appeal you?, Do you quite enjoy taking risks?, Do you take risks or behave unsafely to achieve other objectives?, Would life with no danger in it be too dull for you?, Would you enjoy fast walking underground?, Are you rather cautious in unusual situations?*, Do you always wear safety items when working underground?*, Would you do almost anything for a dare?, Are you confident of assessing good and bad situations underground?*

(5) Emotional instability with 12 items: Does your mind often wander while you try to concentrate on work?, Does your behavior keep changing without any apparent reason?, Do you often remain disappointed and sad?, Do you sometimes feel happy and sometimes depressed for no apparent reason?, Are you quick and sure in your actions?*, Do you have frequent mood swings?, Do you often feel that you have made up your mind too late to do something?, Do you often do your work whole-heartedly (sincerely)?*, Do you feel rather hurt very easily?, Do you like work that requires considerable attention?*, Do you often take your work casually?, Would you rate yourself as a talkative individual?

the research team to the workers. It should be noted that all workers contacted participated in the study.

\section{Statistical analysis}

First, Chronbach's alpha coefficients were computed to measure the intercorrelation of the various items ${ }^{10)}$ for all factors studied: poor perception of working condition, poor safety environment, poor management and supervision, risk taking behavior, emotional instability, negative job involvement, job dissatisfaction, job stress, and poor safety performance. The scores were computed by summing the score of individual items. $90^{\text {th }}$ percentiles of the scores for each trait were used as threshold values: 41 for poor perception of working condition, 31 for poor safety environment, 32 for poor management and supervision, 23 for emotional instability, 23 for negative job involvement, 33 for job dissatisfaction, and 39 for poor safety performance, 32 for job stress and 23 for risk taking behavior. Age was categorized into three groups $(<30,30-45$, and $>45 \mathrm{yr})$ according to the findings of our previous studies ${ }^{35,36}$. Occupational injury was a dependent variable with values of $1=$ Yes and $0=$ No. To assess the effect of various factors on occupational injuries, crude odds ratios (ORs) and their $95 \%$ 
Table 2. The Worker's Response Device (WRD) and Supervisor's Response Device (SRD) questionnaires—continued

(6) Negative Job involvement with 13 items: Are you totally dedicated to your work?*, Does it so happen that how your time spent through work you cannot realize?*, Do you think any loss to your mine is your loss?*, Are you ready to accept any kind of job as and when required?*, Do you get disheartened when you become unsuccessful in your work?*, Are there so many things in life which are more important than your job?, Do you feel your work monotonous?, Do you leave your work irrespective of its importance when the time is over?, Do you consider your work as a burden to you?, Do you feel proud to tell others that you are a part of this mine?*, Do you feel very little loyalty to this mine?, Do you care about the fate of this mine?*, Do you feel you are not fit for this mine?

(7) Job dissatisfaction with 15 items: Are you satisfied with the condition of your work place?*, Are your co-workers co-operative and helpful?*, Do you think your job is respected by other persons?*, Is there any prospect in your job?*, Are the promotions of workers given with justice and honesty?*, Do you think you have got the right job for yourself?*, Does your officer appreciate your competency and quality?*, Do you think your work is difficult and arduous?, Do most workers work from compulsion and fear?, Do you think the workers get right behavior which they expect from their officers?*, If you get an opportunity would you like to leave this company and join another Company?, Are you doing this job as you are getting sufficient salary in spite of your disliking this job?, Do you think this work is a source of respect for a man like you?*, Are you allowed to make decision independently regarding your job?*, Are you happy with your family?*

(8) Job stress with 14 items: Do you have to work hard in your mining job?, Do you think your job is difficult and arduous?, Do you think you have to work in a hurry due to an excess load of work?, Do the other members of your family depend on you?, Is the mining work boring and monotonous?, Have you got a clear idea of your work and its results?*, Does your boss take care of your dignity?*, Do you have a salary adequate for your labour?*, Is your work full of danger?, Does a co-worker try to defame you?, Do you feel you have responsibility for the development of the mine?, Do your co-workers spontaneously help you to solve any problem in the mine?*, Do you feel your service is a burden to you?, Are you happy with the working situation of the mine?*

Supervisor's Response Device (SRD) questionnaire:

Poor safety performance (of worker) with 17 items: Does the worker wear safety items?*, Do you consider the worker is emotionally instable?, Is the worker an alcoholic?, Are the working conditions conducive to safe working?*, Is taking risks, short-cuts or unsafe behavior (does not follow safe work practices) practised by the worker?, Do you consider the worker is always impulsive?, Is the worker totally dedicated to his work?*, Has the worker the ability to work safely without supervision?*, Is the worker tense (stressed) during work?, Is he prone to accident?, Is the worker adequately trained to perform the job safely?*, Is the worker suited to the job he is doing?*, Is the worker motivated to work sincerely and safely at his workplace?*, Is the worker undisciplined in his work?, Does the worker venture under an unsupported roof?, Has the worker a tendency to overloading on the job?, Is the worker careless in his work?

confidence intervals were computed. Adjusted odds ratios (ORs) and $95 \%$ confidence intervals were then computed by the logistic regression method. As marked difference in injuries was observed between loaders and other than loaders (loaders suffered $69.4 \%$ of the total injuries), the interaction effects of job on other risk factors were investigated with the logistic model. All the analyses were performed with the SPSS package ${ }^{37)}$.

\section{Results}

The internal coherences of the questionnaire items of the factors were measured by Chronbach's alpha coefficients. They were as follows: poor perception of working conditions $(0.83)$, poor safety environment $(0.83)$, poor management and supervision (0.86), risk taking behavior (0.74), emotional instability (0.80), negative job involvement (0.73), job dissatisfaction $(0.95)$, job stress $(0.78)$ and poor safety performance $(0.88)$.
Table 3 shows that significant differences were observed between the cases and controls for all the factors studied for all the samples and the loaders. Similar differences were found in other-than-loaders, but they were not significant for age, poor perception of working conditions, emotional instability or for negative job involvement, probably due to the small number of subjects. Table 4 shows the crude odds ratios and the adjusted odds ratios of various factors for all the workers combined. Significant crude odds ratios were found for emotional instability $(3.89,95 \%$ CI $1.86-8.10)$, poor perception of the safety environment (3.64, 1.34-1.99), poor safety performance $(3.27,1.60-6.69)$, job stress (2.77, 1.62-4.73), job dissatisfaction (2.61, 1.38-4.95), poor perception of working conditions $(2.45,1.35-4.44)$, poor management and supervision $(2.11,1.18-3.77)$, negative job involvement $(2.09,1.15-3.78)$ and age $>45$ yr (vs. age $<30 \mathrm{yr}, 2.07,1.17-3.64$ ). Note that the $30-45$ 
Table 3. Characteristics of the cases and controls (\%)

\begin{tabular}{|c|c|c|c|c|c|c|c|c|c|}
\hline & \multicolumn{3}{|c|}{$\begin{array}{c}\text { All the samples } \\
\text { (202 case-control pairs) }\end{array}$} & \multicolumn{3}{|c|}{$\begin{array}{c}\text { Loaders } \\
\text { (140 case-control pairs) }\end{array}$} & \multicolumn{3}{|c|}{$\begin{array}{l}\text { Other-than-loaders } \\
\text { (62 case-control pairs) }\end{array}$} \\
\hline & $\begin{array}{l}\% \text { of } \\
\text { cases }\end{array}$ & $\begin{array}{c}\% \text { of } \\
\text { controls }\end{array}$ & $\begin{array}{l}\text { Comparison of } \\
\text { the two groups }\end{array}$ & $\begin{array}{l}\% \text { of } \\
\text { cases }\end{array}$ & $\begin{array}{c}\% \text { of } \\
\text { controls }\end{array}$ & $\begin{array}{l}\text { Comparison of } \\
\text { the two groups }\end{array}$ & $\begin{array}{l}\% \text { of } \\
\text { cases }\end{array}$ & $\begin{array}{c}\% \text { of } \\
\text { controls }\end{array}$ & $\begin{array}{l}\text { Comparison of } \\
\text { the two groups }\end{array}$ \\
\hline \multicolumn{10}{|l|}{ Age (yr) } \\
\hline$<30$ & 15.8 & 25.3 & & 19.3 & 29.3 & & 8.1 & 16.1 & \\
\hline $30-45$ & 49.5 & 48.0 & $p<0.05$ & 47.9 & 45.7 & $p<0.05$ & 53.2 & 53.2 & NS \\
\hline$>45$ & 34.7 & 26.7 & & 32.9 & 25.0 & & 38.7 & 30.6 & \\
\hline \multicolumn{10}{|l|}{ Poor perception } \\
\hline of working condition & 19.3 & 8.9 & $p<0.01$ & 21.4 & 10.0 & $p<0.01$ & 20.5 & 10.5 & NS \\
\hline Poor safety environment & 17.3 & 5.4 & $p<0.001$ & 21.4 & 7.1 & $p<0.01$ & 19.1 & 7.9 & $p<0.01$ \\
\hline $\begin{array}{l}\text { Poor management and } \\
\text { supervision }\end{array}$ & 18.8 & 9.9 & $p<0.05$ & 17.9 & 11.4 & $p<0.05$ & 17.9 & 11.4 & $p<0.05$ \\
\hline Risk taking behavior & 14.9 & 8.9 & $p<0.05$ & 17.9 & 11.4 & $p<0.05$ & 24.5 & 9.4 & $p<0.001$ \\
\hline Emotional instability & 16.8 & 5.0 & $p<0.001$ & 25.0 & 9.7 & $p<0.001$ & 21.0 & 11.6 & NS \\
\hline Negative job involvement & 17.8 & 8.9 & $p<0.05$ & 17.1 & 9.3 & $p<0.05$ & 18.1 & 10.3 & NS \\
\hline Job dissatisfaction & 17.3 & 9.4 & $p<0.01$ & 17.9 & 8.6 & $p<0.05$ & 19.9 & 8.2 & $p<0.05$ \\
\hline Job stress & 26.2 & 7.4 & $p<0.001$ & 27.9 & 12.9 & $p<0.01$ & 18.9 & 11.3 & $p<0.01$ \\
\hline Poor safety performance & 15.8 & 11.4 & $p<0.001$ & 26.8 & 10.4 & $p<0.001$ & 21.6 & 9.9 & $p<0.01$ \\
\hline
\end{tabular}

NS: non significant

Table 4. Relationships between various factors and all injuries combined (202 case-control pairs): crude odds ratios, adjusted odds ratios and $95 \%$ confidence intervals (threshold values are defined by the $90^{\text {th }}$ percentiles in controls)

\begin{tabular}{lllll}
\hline & \multicolumn{2}{c}{$\begin{array}{c}\text { Crude odds ratio and } \\
95 \% \text { confidence interval }\end{array}$} & \multicolumn{2}{c}{$\begin{array}{c}\text { Adjusted odds ratio and } \\
95 \% \text { confidence interval }\end{array}$} \\
\hline Age (yrs) & & & & \\
$\quad 30-45$ vs. $<30$ & 1.64 & $(0.97-2.77)$ & $1.80^{\mathrm{a}}$ & $(1.02-3.17)$ \\
$>45$ vs. $<30$ & $2.07^{\mathrm{a}}$ & $(1.17-3.64)$ & $2.59^{\mathrm{b}}$ & $(1.38-4.85)$ \\
Poor perception of working conditions & $2.45^{\mathrm{b}}$ & $(1.35-4.44)$ & $1.61^{\mathrm{a}}$ & $(1.00-3.18)$ \\
Poor safety environment & $3.64^{\mathrm{b}}$ & $(1.34-1.99)$ & 1.66 & $(0.67-4.08)$ \\
Poor management and supervision & $2.11^{\mathrm{a}}$ & $(1.18-3.77)$ & 1.15 & $(0.57-2.34)$ \\
Risk taking behavior & 1.78 & $(0.96-3.32)$ & 1.12 & $(0.53-2.37)$ \\
Emotional instability & $3.89^{\mathrm{c}}$ & $(1.86-8.10)$ & $2.33^{\mathrm{a}}$ & $(1.04-5.22)$ \\
Negative job involvement & $2.09^{\mathrm{a}}$ & $(1.15-3.78)$ & 1.29 & $(0.66-2.53)$ \\
Job dissatisfaction & $2.61^{\mathrm{b}}$ & $(1.38-4.95)$ & 1.21 & $(0.55-2.64)$ \\
Job stress & $2.77^{\mathrm{c}}$ & $(1.62-4.73)$ & $1.83^{\mathrm{a}}$ & $(1.00-3.46)$ \\
Poor safety performance & $3.27^{\mathrm{c}}$ & $(1.60-6.69)$ & $3.10^{\mathrm{c}}$ & $(1.45-6.63)$ \\
\hline
\end{tabular}

${ }^{\mathrm{a}} p<0.05,{ }^{\mathrm{b}} p<0.01,{ }^{\mathrm{c}} p<0.001$.

yr age group and risk taking behavior had crude odds ratios close to a significant level. Of the factors considered five factors had significant adjusted odds ratios: older ages $(1.80,95 \%$ CI $1.02-3.17$ and 2.59, 1.384.85 for the $30-45$ and $>45 \mathrm{yr}$ age groups respectively), emotional instability $(2.33,1.04-5.22)$, job stress (1.83, $1.00-3.46)$, poor perception of working conditions (1.61,
$1.00-3.18)$ and poor safety performance $(3.10,1.45-$ $6.63)$.

Table 5 shows the adjusted odds ratios for the main effects of the risk factors and the interactive effects of these risk factors with the job. Although none of the interactive terms were significant, it should be noted that they were noticeably higher than 1 for emotionally 
Table 5. Logistic model with interaction effects of the risk factors with job

\begin{tabular}{|c|c|c|}
\hline & $\begin{array}{l}\text { Adjusted } \\
\text { odds ratio }\end{array}$ & $\begin{array}{c}95 \% \\
\text { confidence interval }\end{array}$ \\
\hline \multicolumn{3}{|l|}{ Main Effects } \\
\hline \multicolumn{3}{|l|}{ AGE } \\
\hline AGE1 & 1.88 & $0.94-3.77$ \\
\hline AGE2 & $2.50^{\mathrm{a}}$ & $1.18-5.26$ \\
\hline WC & 1.37 & $0.60-3.14$ \\
\hline SE & 2.25 & $0.77-6.60$ \\
\hline MS & 1.47 & $0.66-3.31$ \\
\hline RT & 1.56 & $0.64-3.81$ \\
\hline EI & 1.72 & $0.67-4.39$ \\
\hline JI & 1.18 & $0.56-2.46$ \\
\hline JD & 1.64 & $0.62-4.39$ \\
\hline JSTR & 1.62 & $0.73-3.63$ \\
\hline SP & $2.34^{\mathrm{a}}$ & $1.00-5.47$ \\
\hline \multicolumn{3}{|l|}{ Interactions } \\
\hline AGE1*JOB & 0.91 & $0.48-1.74$ \\
\hline AGE2*JOB & 0.95 & $0.46-1.97$ \\
\hline $\mathrm{WC} * \mathrm{JOB}$ & 1.21 & $0.53-2.76$ \\
\hline SE*JOB & 0.84 & $0.29-2.46$ \\
\hline MS*JOB & 0.57 & $0.26-1.28$ \\
\hline RT*JOB & 0.62 & $0.26-1.48$ \\
\hline EI*JOB & 2.11 & $0.85-5.27$ \\
\hline $\mathrm{JI} * \mathrm{JOB}$ & 1.04 & $0.50-2.17$ \\
\hline $\mathrm{JD} * \mathrm{JOB}$ & 0.68 & $0.26-1.81$ \\
\hline JSTR*JOB & 1.14 & $0.51-2.55$ \\
\hline $\mathrm{SP} * \mathrm{JOB}$ & 1.57 & $0.71-3.47$ \\
\hline
\end{tabular}

AGE: age, AGE1: 30-45 vs. <30, AGE2: $>45$ vs. <30, WC: poor perception of working conditions, SE: poor safety environment, MS: poor management and supervision, RT: risk taking behavior, EI: emotional instability, JI: negative job involvement, JD: job dissatisfaction, JSTR: job stress, SP: poor safety performance, JOB: job category $(=1$ for loaders and 0 for other-than-loaders, reference category is other-thanloaders) ${ }^{\mathrm{a}} p<0.05,{ }^{\mathrm{b}} p<0.01,{ }^{\mathrm{c}} p<0.001$.

instability and poor safety performance, and noticeably lower than 1 for poor management and supervision, risk taking behavior and job dissatisfaction.

\section{Discussion}

This survey was a case-control study on coal miners randomly selected from among the workers in a coal company. In this study efforts were made to eliminate selection bias in the sample. As the risk of injury is much higher in loaders than in other workers, random selection of the cases and their controls was done on the basis of their occupation (loaders and other-than-loaders) so that the distribution of the cases and controls according to occupation was close to that of all injuries in the mines.
All underground workers were male. It should be noted that fatal and serious injuries ( 2 and 17 respectively for the period studied, 1996-2000, 2.4\% of total injuries) were excluded from the study due to its protocol: the risk factors concerned underground working condition, and the miners with serious injuries had been shifted to less hazardous and laborious jobs on the surface. This would introduce a bias due to the well-known healthy worker effect. But it would not greatly change the results as the percentage of subjects concerned was small (2.4\%). Furthermore, the workers who had left the mines were lost to the study. This also introduced a bias as health status is a risk factor in occupational injury ${ }^{38)}$; so, interpretation of the results must be made with prudence. An auto questionnaire survey was avoided and face-toface interviews were conducted so that workers did not face any difficulty in responding the questionnaire items.

It should be noted that the internal coherence of the questionnaires for various factors was very good. Indeed high Chronbach's alpha coefficients were found (between 0.73 and 0.95). It reported that older ages, poor perception of working conditions, poor safety environment, poor management and supervision, risk taking behavior, emotional instability, negative job involvement, job dissatisfaction, job stress, and worker's poor safety performance played noticeable roles in occupational injuries. The job, which is a well known risk factor ${ }^{5,6,38)}$, was not investigated in this study as the cases and controls were matched on the basis of it. The survey used validated questionnaires previously utilized in various countries $4,8,10,15,20,22-32,34)$. The questionnaires were administered by individual interviewers. It should be noted that all the management of the mines and all the workers contacted participated in the study. The survey was well accepted by the miners.

The present study reported that a higher risk of injuries was observed in older workers. This was also reported by other researchers ${ }^{4,35}$. Ageing would result in a decrease in physical and mental abilities which may in turn alter the quality of work performance and the ability to notice work environment hazards, particularly when the demanding level of the tasks is high, but some discrepancies were found by some studies. Maiti and Bhattacherjee found no significant difference between age groups ${ }^{6}$. Gauchard et al. also found no difference for injuries due to falls ${ }^{14)}$. Chau et al., Bazroy et al., and Ghosh et al., showed that younger subjects had a higher risk $^{11,18,39)}$. Young age is associated to lack of knowledge, lack of experience and contributes to risk taking behavior; this hypothesis would explain why the causes of injuries differed according to the age group ${ }^{12)}$. Although in this study age was considered as a risk factor and was controlled in the logistic regression analysis, it might have been better to collect the samples by matching the age of case and control groups, because age is a well known 
risk factor ${ }^{40)}$.

This study found that poor perception regarding working conditions and safety environment had a significant influence on injury occurrence. This finding suggests that workers who are highly satisfied with the existing working conditions have a lower risk. It was confirmed by discussions with workers that workers with no injury have positive thinking about the physical environment and always take necessary safety precautions. This was also observed by other researchers. Li et al. emphasized that workplace injuries are caused by a poor person-environment fit $^{10)}$, which leads to increased job stress and therefore to increased injury risk. Melamed et al. stressed that individuals who are more sensitive to the work environment are more likely to have been involved in injuries ${ }^{22)}$, but working condition, the environment and management also play important roles. Melamed et al. suggested that pre-occupation with disturbing job and work environment characteristics are important contributors to occupational injuries ${ }^{22}$. This pre-occupation may serve as a directing factor making the workers less attentive to danger cues. Li et al. expressed poor working conditions in terms of work stressors which cause mental disturbance and consequently occupational injuries ${ }^{10)}$. Stressful jobs or increased intensity of occupational stressors may increase the risk of occupational injury ${ }^{10,27,32)}$. A poor safety environment is partly due to defective plant, equipment, tools, materials and buildings. Studies have shown that perception of a safety climate predicts safety knowledge and motivation, and safety behavior which in turn are predictors of occupational injuries ${ }^{20,24)}$. The role found in injuries for poor management and supervision was expected. Indeed, the attitudes of management in support of achieving production targets can affect worker behavior. Our finding was consistent with that by some researchers who reported that management could affect the health status and safety of employees and increase the risk of accidents ${ }^{8,23)}$.

An important finding of our study is that workers with emotional instability have a higher risk of occupational injuries. This result was consistent with that from other authors ${ }^{4,28)}$. Emotional instability is defined as excessive emotional reactivity associated with frequent changes or swings in emotions and mood. Frone suggested that negative emotional states and a lack of emotional stability may lead to lapses in attention or to higher levels of distractibility, thereby increasing the risk of injury ${ }^{27)}$. It may be indicated that the jobs in underground mines can be sometimes stressful. This stress creates frustrations which can alter the adjustive responses, and consequently the reactions can be disorganized or exaggerated. Such situations can increase the risk of injuries ${ }^{27}$.

The higher risk of occupational injuries among jobdissatisfied workers found in the present study confirms the results from other investigations ${ }^{10,28,31)}$. Job dissatisfaction can be considered as an emotional response and represents job related strain which is associated with production, motivation, absenteeism, tardiness, carelessness, fatigue and mental health which in turn cause injuries.

Negative job involvement was also found to play a positive role in occupational injuries. This result would be explained by the fact that workers who are negatively involved are not satisfied with their job, which result in injuries ${ }^{41,42)}$.

A marked risk was found for workers with poor safety performance. The study revealed that the control group evinced better safety performance than the injured workers due to their positive psychological traits and characteristics. According to the supervisors, individual production bonuses sometimes encouraged workers to take risks. Dhar found a similar result with a similar questionnaire rated by the respective supervisors of workers ${ }^{33)}$.

Initially it was suspected that the job (loaders and other than loaders) may have different effects on the risk factors but the results obtained with the logistic regression model have revealed that the job has no significant effect on the risk factors.

It should be mentioned that the comparison of our results with those obtained by other authors has to be made with caution. Indeed, there are marked sociocultural differences between the subjects investigated and those of the other studies. Moreover, the populations and the professional sectors could also be different.

In conclusion, our study reported that older age, emotional instability, poor perception of working condition, job stress and poor safety performance of worker play significant roles in occupational injuries. This valuable information would help in implementing preventive programs in which firms, workers and researchers have to work together in partnership. Work conditions have to be improved. The management should pay attention to the problems of the working environment and safety of workers. Workers should be trained to develop positive psychological traits to maintain the balance between rigidity and flexibility which is helpful in injury prevention. Factors which affect the psychological traits negatively should be reinforced. Workers with negative traits such as emotional instability and older workers should be employed in less demanding jobs.

Acknowledgments: The authors wish to acknowledge the financial support provided by the Ministry of Human Resource Development (MHRD), Government of India for conducting this study. They also wish to acknowledge MHRD project team members especially Prof. M.B. Sharan, Prof. S.C. Ray and Prof. S.K. Mukhopadhyay 
for their contribution to this study. The support from the management, staff and workers of the case study mines is gratefully appreciated.

\section{References}

1) Saari J. Accident prevention. In: International Labour Office, ed. Encyclopaedia of Occupational Health and Safety. Vol. 2, 4th edition. Genova: ILO, 1998: 56.156.2

2) Kisner SM. Work-related fatalities in the United States: 1980-1995 a sixteen year picture. In: Injury Prevention and Control, Proceedings of $5^{\text {th }}$ International Conference, Delhi, 2000: 779.

3) N Stout and H Linn: From strategy to reality: 25 years of planning and progress in occupational injury research. Inj Prev 7 (suppl I), i11-i14 (2001)

4) RD Iverson and PJ Erwin: Predicting occupational injury: the role of affectivity. J Occup Organ Psychol 70, 113-128 (1997)

5) J Maiti and A Bhattacherjee: Predicting accident susceptibility: a logistic regression analysis of underground coal mine workers. J S Afr Inst Min Metall 101, 203-208 (2001)

6) J Maiti, A Bhattacherjee and SI Bangdiwala: Loglinear model for analysis of cross-tabulated coal mine injury data. Inj Control Safety Promot 8, 229-236 (2001)

7) I Donald and S Young: Managing safety: An attitudinalbased approach to improving safety in organizations. Leadership Organ Develop J 17, 13-20 (1996)

8) DW Hine, J Lewko and J Blanco: Alignment to workplace safety principles: an application to mining. J Safety Res 30, 173-185 (1999)

9) Shaw BE, Sanders MS, Peay J. Research to determine the contribution of system factors including human error in the occurrence of underground injuries. In: Proceedings XVI, Training Resources Applied to Mining, The Pennsylvania State University, University Park, 1989: 14-16, 9-23.

10) CY Li, KR Chen, $\mathrm{CH} \mathrm{Wu}$ and FC Sung: Job stress and dissatisfaction in association with non-fatal injuries on the job in a cross-sectional sample of petroleum workers. Occup Med 51, 50-55 (2001)

11) N Chau, JM Mur, L Benamghar, C Siegfried, JL Dangelzer, M Francais, R Jacquin and A Sourdot: Relationships between some individual characteristics and occupational accidents in the construction industry: a case-control study on 880 victims of accidents occurred during a two-year period. J Occup Health 44, 131-139 (2002)

12) N Chau, G Gauchard, C Siegfried, L Benamghar, JL Dangelzer, M Français, R Jacquin, A Sourdot, PhP Perrin and JM Mur: Relationships of job, age, and life conditions with the causes and severity of occupational injuries in construction workers. Int J Occup Environ Health 77, 60-66 (2004)

13) HJ Lipscomb, JM Dement and R Rodriguez-Acosta: Deaths from external causes of injury among construction workers in North Carolina. Appl Occup Environ Hyg 15, 569-580 (2000)
14) GC Gauchard, N Chau, C Touron, L Benamghar, D Dehaene, PhP Perrin and JM Mur: Individual characteristics in occupational accidents due to imbalance: a case-control study of the employees of a railway company. Occup Environ Med 60, 330-335 (2003)

15) Lee TR, Macdonald SM, Coote JA. Perceptions of risks and attitudes to safety at a nuclear reprocessing plant. Presented at the Society for Risk Assessment (Europe) Fourth Conference, Rome. 1993.

16) K Kim, L Nitz, J Richardson and L Li: Personal and behavioral predictors of automobile crash and injury severity. Accid Anal Prev 27, 469-481 (1995)

17) P Ulleberg and T Rundmo: Personality, attitudes and risk perceptions as predictors of risky driving behaviour among young drivers. Safety Sci 41, 427-443 (2003)

18) J Bazroy, G Roy, A Sahai and MB Soudarssanane: Magnitude and risk factors of injuries in a glass bottle manufacturing plant. J Occup Health 45, 53-59 (2003)

19) BC 3rd Amick, I Kawachi, EH Coakley, D Lerner, S Levine and GA Colditz: Relationship of job strain and iso-strain to health status in a cohort of women. Scand J Work Environ Health 24, 54-61 (1998)

20) DA Hofmann and A Stetzer: A cross-level investigation of factors influencing unsafe behaviors and accidents. Pers Psych 49, 307-339 (1996)

21) D Prosser, S Johnson, E Kuipiers, G Szmukler, P Bebbington and $\mathrm{G}$ Thornicroft: Perceived sources of work stress and satisfaction among hospital and community mental health staff, and their relation to mental health, burnout, and job satisfaction. J Psychos Res 43, 51-59 (1997)

22) S Melamed, D Yekutieli, P Froom, E Kristal-Boneh and J Ribak: Adverse work and environmental conditions predict occupational injuries: the Israeli cardiovascular occupational risk factors determination in Israel (cordis) study. Am J Epidemiol 150, 18-26 (1999)

23) Braithwaire J. To punish or persuade. In: Enforcement of Coal Mine Safety. Albany: State University of New York Press, 77-169 (1985)

24) MA Griffin and A Neal: Perceptions of safety at work: a framework for linking safety climate to safety performance, knowledge and motivation. J Occup Health Psychol 5, 347-358 (2000)

25) WA Harrell: Injury history and perceived risk of injury as factors influencing fatalism about occupational injuries. Percept Motor Skills 81, 665-666 (1995)

26) R Lawton and D Parker: Individual differences in accident liability: a review and integrative approach. Hum Factors 40, 655-672 (1998)

27) MR Frone: Predictors of work injuries among employed adolescents. J Appl Psychol 83, 565-576 (1998)

28) C Zwerling, NL Sprince, RB Wallace, CS Davis, PS Whiten and SG Heeringa: Risk factors for occupational injuries among older workers: an analysis of the health and retirement study. Am J Publ Health 86, 1306-1309 (1996)

29) TA Judge, JE Bono and EA Locke: Personality and job 
satisfaction: the mediating role of job characteristics. J Appl Psychol 85, 237-249 (2000)

30) EA Locke, K McClear and D Knight: Self-esteem and work. Int Rev Ind Org Psychol 11, 1-32 (1996)

31) ML Holcom, WEK Lehman and DD Simpson: Employee accidents: influences of personal characteristics, job characteristics, and substance use in jobs differing in accident potential. J Safety Res 24, 205-221 (1993)

32) JJ Johnston: Occupational injury and stress. J Occup Environ Med 37, 1199-1203 (1995)

33) Dhar BB, Singh AP, Ratan S: Socio-psychological correlation of coal mine accidents. In: Proceedings of the $27^{\text {th }}$ International Conference of Safety in Mines Research Institutes, New Delhi, 1990: 20-22, 12391252.

34) Breslow NE, Day NE. Statistical methods in cancer research. Vol. II. The design and analysis of cohort studies. IARC Scientific Publication, No. 82, Lyon, 1987.

35) Bhattacherjee A, Ray SC, Mukhopadhyay SK, Saran MB, Ghosh AK. Mine safety management: an investigation of accident prone mines with special reference to human behavioural accidents. In: MHRD Project Report, Dept Min Engg IIT Kharagpur, India, 2002: 95-107.
36) AK Ghosh and A Bhattacherjee: Role of individual characteristics of workers in mine accidents: a casecontrol study. Minetech 24, 43-48 (2003)

37) Statistical Package for the Social Sciences (SPSS 10), Inc. Chicago IL: SPSS Reference Guide, 1999.

38) A Bhattacherjee, N Chau, C Otero Siera, B Legras, L Benamghar, JP Michaely, AK Ghosh, F Guilemin, JF Ravaud, JM Mur and Lorhandicap group: Relationships of job and some individual characteristics with occupational injuries in employed people: A community-based study, J Occup Health 45, 382-391 (2003)

39) A Ghosh, A Bhattacherjee and SC Ray: An application of system dynamics in mine safety studies. Min Res Eng 7, 131-147 (1998)

40) Rosner B. Confounding and standardization, In: Fundamentals of Biostatistics. 5th Ed. Duxbury Press, 2000: 591-596.

41) AJ Farkas and LE Tetrick: A three-wave longitudinal analysis of the causal ordering of satisfaction and commitment on turnover decisions. J Appl Psychol 74, 855-868 (1989)

42) LJ Williams and JT Hazer: Antecedents and consequences of organizational turnover: a reanalysis using structural equations model. J Appl Psychol 71, 219-231 (1986) 